\title{
Erratum to: Reframing Resolution
}

\section{Richard Saundry • Paul Latreille • Ian Ashman}

\section{DOI 10.1057/978-1-137-51560-5}

The foreword which is missing in the book is given below:

\section{FOREWORD}

In the public and policy imagination, conflict at work has perhaps tended to be pigeon-holed as synonymous with industrial action. It is true that strikes - threatened and actual—were important markers in the manifestation of conflict across the lion's share of the last century and this remains the case albeit with reduced incidence. But workplace conflict is a more complex phenomenon than this. Conflict can be a response to

The updated original online version for this book can be found at DOI 10.1057/978-1-137-51560-5 
a very varied set of influences. These include the economic and policy environment in which organisations operate through to a response to a perceived imbalance in power relations, or simply a difference of opinion between individuals.

It follows that the question of how to manage conflict, and resolve disputes, is central to organisational effectiveness, and requires the kind of strategic approach currently followed for other business and operational questions. And beyond the workplace itself, conflict management remains an important area for research and empirical investigation. Acas recognises the value of both best practice inside the workplace and the significant role that research and analysis can play in shaping the future of this agenda. Indeed, the knowledge gained from practical experience and research has always been crucial to informing Acas' approach to fulfilling its statutory responsibilities. These duties, set out 40 years ago in the Employment Protection Acas of 1975, are the promotion of good industrial relations and providing assistance to support parties in resolving differences through conciliation, mediation and arbitration services.

Our commitment to excellence in these areas, promoting productive workplaces and a high quality of working life, remains our central concern. We learn about what works best through our daily exposure to workplaces, but also through research and analysis of trends and behaviours. And I am delighted to see much of the Acas commissioned research featured in this publication.

There are some aspects of the conflict at work that we are well sighted on. For instance, the Office for National Statistics manages an important data source on the incidence of strikes in the UK, and the Employment Tribunal statistics alongside Acas data provide a record of aspects of collective and individualised workplace conflict. The internationally recognised Workplace Employment Relations Studies, dating back to 1980, provides a supplementary evidence base on the incidence of conflict via the prism of the workplace. All these sources are reviewed in this volume and presented alongside informed commentary and analysis. This evidence is supplemented by data from overseas, and by evidence from surveys and qualitative data from a multitude of projects. Collectively they provide a rich picture of trends in conflict, and the evolving nature of dispute resolution. There are also some longstanding gaps in what we 
know about conflict at work. These include the availability of systematic data on the incidence of less visible forms of conflict, and disputes that remain unaddressed but which nonetheless have a potentially damaging impact on workplace relations. This volume is particularly important for identifying gaps in our knowledge and helping to shape the future research agenda.

The depth and breadth of the book, its rigour and insight, are commendable. In our fortieth year, the volume offers a timely contribution in assisting Acas to reflect on the structural, policy and practical influences that have shaped the way conflict is handled in the modern workplace. This will provide a vital resource as we look to the future and to development of conflict management strategies that fit with organisations and reflect the changing world of work. Crucially, the book makes important observations about the diffusion of new practices. We are particularly attracted to those practical solutions that offer expedient and nonadversarial routes to addressing disputes. The further embedding of such practices, and the value of identifying new approaches, offers a challenge for Acas, and others with an interest in workplace relations. And this volume will provide a starting point for stimulating debate and improving practice.

I believe that the value of this important publication will soon be recognised by all those with an interest in this vital field of enquiry. I am grateful to all the contributors for their work, and particularly to the editors for their individual contributions to this field of enquiry over a protracted period. 